\title{
$\mathrm{ZnSb}$ の熱電特性に対するテルル元素添加効果*1
}

\author{
上田貴史 ${ }^{2}$ 岡村千夏*2 野田泰稔 長谷崎和洋
}

島根大学総合理工学部

J. Japan Inst. Metals, Vol. 74, No. 2 (2010), pp. 110-113

(C) 2010 The Japan Institute of Metals

\section{Effect of Tellurium Doping on the Thermoelectric Properties of ZnSb}

Takashi Ueda*2, Chinatsu Okamura*2, Yasutoshi Noda and Kazuhiro Hasezaki

Department of Materials Science, Shimane University, Matsue 690-8504

\begin{abstract}
$n$-type tellurium doped $\mathrm{ZnSb}$ was prepared by direct melting at $923 \mathrm{~K}$ after which it was quenched in water within an evacuated quartz ampoule. All the ingots were heat treated at $723 \mathrm{~K}$ for $100 \mathrm{~h}$. The resultant samples were characterized by Xray diffraction (XRD), differential thermal analysis (DTA) and by measurement of their Seebeck and Hall coefficients. XRD and DTA indicated that the solubility limit of tellurium in $\mathrm{ZnSb}$ was less than 3 at $\%$. The samples with 0,1 and 3 at $\%$ tellurium were $p$-type while those with 1.90 and 2.06 at\% tellurium were $n$-type. These results indicated that $n$-type $\mathrm{ZnSb}$ samples can be obtained by the proper doping of tellurium. Excess doping with tellurium resulted in precipitation of the $\mathrm{ZnTe}$ phase and a change in conduction from $n$ - to $p$-type. The maximum power factor for the 2.06 at $\%$ tellurium doped $n$-type sample was found to be $0.84 \times 10^{-3} \mathrm{Wm}^{-1} \mathrm{~K}^{-2}$ at $573 \mathrm{~K}$.
\end{abstract}

(Received October 2, 2009; Accepted October 29, 2009)

Keywords: thermoelectric semiconductor, zinc antimonide, tellurium, n-type, Seebeck coefficient

\section{1. 緒言}

$\mathrm{ZnSb}$ 熱電半導体は，450-700 K の中低温領域で高い熱電 性能を持つ $p$ 型半導体材料として知られている1).ここで熱 電半導体の性能を示すパワーファクターは $\alpha^{2} \sigma$ で定義され, $\alpha$ はゼーベック係数 $(\mathrm{V} / \mathrm{K}), \sigma$ は電気伝導率 $(\mathrm{S} / \mathrm{m})$ である. $\mathrm{ZnSb}$ 熱電半導体は, 原材料価格が比較的安価なことから, 有害な鉛を含む高性能な鉛テルル系熱電材料に置き換わる可 能性を有している. その優れた特徴を活かして 1950 年代に M. Telks 等は, $p$ 型 $\mathrm{ZnSb}$ 熱電半導体について, 太陽熱-熱 電発電システムの研究が行われた 2,3$)$. 国内㧍いても, 1960 年代に増本剛等の $\mathrm{ZnSb}$ 単結晶育成に関する先駆的な研究が 行われた ${ }^{4,5)}$.

$\mathrm{ZnSb}$ 相は, $819 \mathrm{~K}$ で包晶反応により得られる物質であ り6), 単相の $\mathrm{ZnSb}$ を得るには長時間の熱処理が必要とされ ている。これまでの報告においても, 単相の ZnSb 試作が非 常に困難であるとされている7,8).

さらに, 熱電モジュールは, 一般に $p$ 型と $n$ 型半導体の ペアを有する構造を持つ. $n$ 型 $\mathrm{ZnSb}$ の添加元素の影響に関 する研究において ${ }^{9,10)}, 1971$ 年にテルル元素を添加すること により $n$ 型 $\mathrm{ZnSb}$ 単相が得られた ${ }^{11)}$. しかしながら, 添加量 については明らかにされて抢らず，さらに $n$ 型 $\mathrm{ZnSb}$ 単相合 成は再現性に乏しく, その後の $n$ 型 $\mathrm{ZnSb}$ 単相合成例は調査 の限り皆無であり，そのため実用化に至っていない。

\footnotetext{
*1 Mater. Trans. 50(2009) 2473-2475 に揭載

*2 島根大学大学院生 (Graduate Student, Shimane University)
}

本研究では, テルル元素を添加することにより, $n$ 型 $\mathrm{ZnSb}$ の作製を試みた。 サンプルは, 直接溶解後急冷し, そ の後熱処理することで試作した. テルル元素の添加量は, 0 〜3 at\%とした.これらの試作から $\mathrm{ZnSb}$ の導電タイプが 型から $n$ 型に変化することを見出し, $n$ 型導電性を示すテル ル添加量領域を明らかにした。

\section{2. 実 験 方 法}

無添加およびテルル添加の単相 $\mathrm{ZnSb}$ の試作は構成元素を 直接溶解しその後水中に急冷し, さらに熱処理を行うことに より行った. 各構成元素 $\mathrm{Zn}, \mathrm{Sb}, \mathrm{Te}$ の純度は $5 \mathrm{~N}$ であり, テルル元素の添加量は, $0 \sim 3$ at $\%$ とした. 秤量後, 石英管 に真空封入したアンプルを，973 K, 3 時間加熱溶解し, 水 中に投下し急冷を行った. その後, アンプル中で $723 \mathrm{~K} に$ 加熱し，100 時間熱処理することでインゴットを得た. 熱処 理は包晶反応により単相を得るためである．得られたサンプ ルの解析は, $\mathrm{X}$ 線回折 $(\mathrm{XRD})$ 及び示差熱分析 (DTA)を用い て行った. XRD は $\mathrm{Cu}-\mathrm{K} \alpha$ 線を用い $2 \theta$ は $20 〜 50^{\circ}$ とした. DTA 測定は窒素気流中でアルミナ容器を用い, $20 \mathrm{~K} / \mathrm{min}$ の昇温速度で $300 \mathrm{~K}$ から $873 \mathrm{~K}$ まで昇温して行った。

ゼーベック係数 $\alpha$ は, 熱起電力 $(E)$ の線形性が確保されて いるとして, 真空中で温度差 $(\Delta T)$ を $3 \mathrm{~K}$ まで与えて $\alpha=E /$ $\Delta T$ の関係から求めた. 測定範囲は, $300 \mathrm{~K}$ から $600 \mathrm{~K}$ であ る. ホール係数 $R_{\mathrm{H}}$ と電気伝導率 $\sigma$ は, ホール電流 $5 \mathrm{~mA}$, 磁場 $0.5 \mathrm{~T}$ の条件で, 真空中 van der Pauw 法により測定し た.これもゼーベック係数と同様に測定範囲は, $300 \mathrm{~K}$ から 
$600 \mathrm{~K}$ である。キャリア濃度 $n$ は, $n=1 / e R_{\mathrm{H}}$ より求め, キ ヤリア移動度 $\mu$ は $\mu=R_{\mathrm{H}} \sigma$ から求めた. ここで $e$ は, 電気素

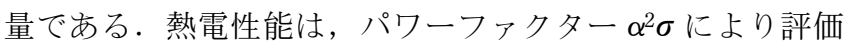
した.

\section{3. 結果および議論}

\section{1 テルル元素の添加量依存性}

Fig. 1-(1) および 1-(2)に (a) 0, (b) 1, (c) 1.9, (d) 2.06,

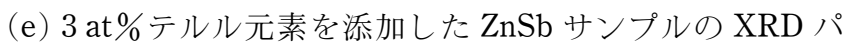
ターンを示す。1-(1)では $2 \theta$ は 20〜50 であるのに対して, 1-(2)では $2 \theta$ は 38〜 41である. Fig. 1(a)-(e)のほとんど の回折ピークが $\mathrm{ZnSb}$ 相の回折ピークと一致するのに対して, Fig. 1 (e)に示す $40^{\circ}$ 付近の回折ピークは, ZnTe 相に一致し

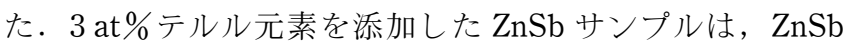
相と ZnTe 相の二相から構成されていることを Fig. 1(e)は 示している. ZnSbに添加した過剰なテルルは, ZnTe とし て析出しているものと推定される. Fig. 1(d)と（e)から， $\mathrm{ZnSb}$ のテルル固溶限は, 3 at $\%$ 未満であることを示してい る.

$\mathrm{ZnSb}$ サンプルの DTA 昇温曲線を Fig. 2 に示す.ここ で，テルル元素の添加は (a) 0, (b) 1, (c) 1.9, (d) 2.06, (e) 3 at $\%$ とした. 温度上昇に伴い $823 \mathrm{~K}$ に大きな吸熱ピークが 観測された．このピークは, $\mathrm{ZnSb}$ 相の融点に一致した．別 の $780 \mathrm{~K}$ 付近で観察される小さな吸熱ピークは, ZnSb と

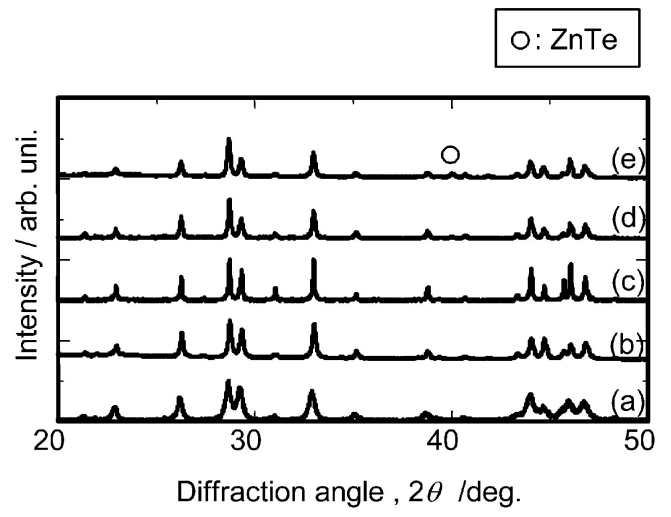

(1) $2 \theta$ was from 20 to 50 degrees

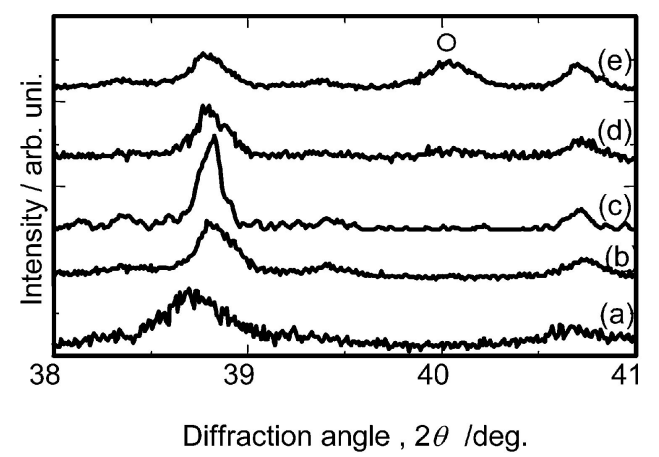

(2) $2 \theta$ was from 38 to 41 degrees

Fig. 1 XRD patterns of the ZnSb samples doped with (a) 0 , (b) 1 , (c) 1.9 , (d) 2.06 and (e) 3 at\% Te and (1) $2 \theta$ was from 20 to 50 degrees, (2) $2 \theta$ was from 38 to 41 degrees.
$\mathrm{Sb}$ の共晶温度に一致した ${ }^{6)}$. 3 at\%テルル元素を添加した場 合, このピークは他の $\mathrm{ZnSb}$ サンプルより大きい傾向が見ら れた.

\section{2 テルル元素を添加した $\mathrm{ZnSb}$ サンプルの熱電特性}

Fig. 3 に室温におけるテルル元素添加量に対するゼーベッ ク係数の測定結果を示す. $0,1,3$ at\%テルル元素を添加した $\mathrm{ZnSb}$ サンプルは, $p$ 型を示した. 一方, $1.9,2.06$ at\%テル ル元素を添加した $\mathrm{ZnSb}$ サンプルは， $n$ 型を示した.つま り, 適切な量のテルル添加を行えば, $n$ 型 $\mathrm{ZnSb}$ が得られる ことを 1.9, 2.06 at\%テルル元素を添加した $\mathrm{ZnSb}$ サンプル は示している. 過剰な Te は, Fig. 1(e)の ZnTe 相の析出の 原因となっている. ZnTe は, 室温で 2.2-2.3 eV の直接遷移 型のバンドギャップを有する半導体で，常に $p$ 型を示すこと が知られている12). したがって, 3 at\%テルル元素を添加し た $\mathrm{ZnSb}$ サンプルは $n$ 型から $p$ 型に導電タイプを変化したと 考えられる.

これ以降の Fig. 4 から Fig. 8 は, 2.06 at\%テルル元素を 添加した $n$ 型サンプルと比較のためのテルル無添加の $p$ 型 サンプルの熱電特性について述べる.

Fig. 4 は， 2.06 at\%テルル元素を添加した $n$ 型サンプルと 比較のためのテルル無添加の $p$ 型サンプルのゼーベック係数 の温度依存性を示す．着目するべき点は, $300 \mathrm{~K}$ から $600 \mathrm{~K}$ にわたりすべての温度領域で, 2.06 at\%テルル元素を添加 したサンプルのゼーベック係数は負の值を示し, この温度領 域で $n$ 型であることである.

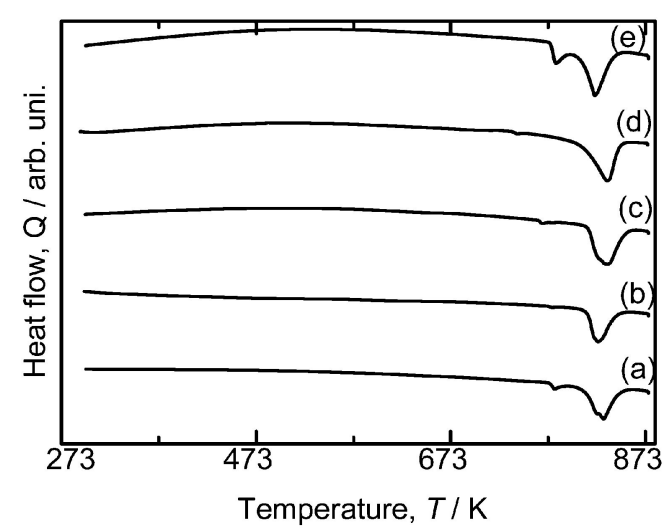

Fig. 2 DTA curves for the $\mathrm{ZnSb}$ samples doped with (a) 0 , (b) 1 , (c) 1.9 , (d) 2.06 and (e) 3 at\% Te.

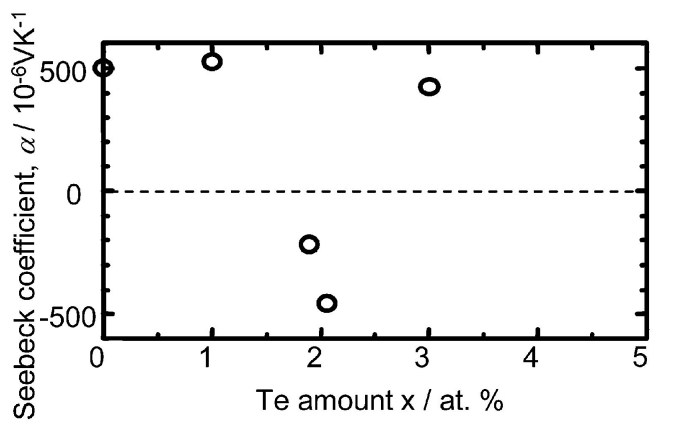

Fig. 3 Seebeck coefficient $\alpha$ versus the tellurium doped amount $x$, measured at room temperature. 


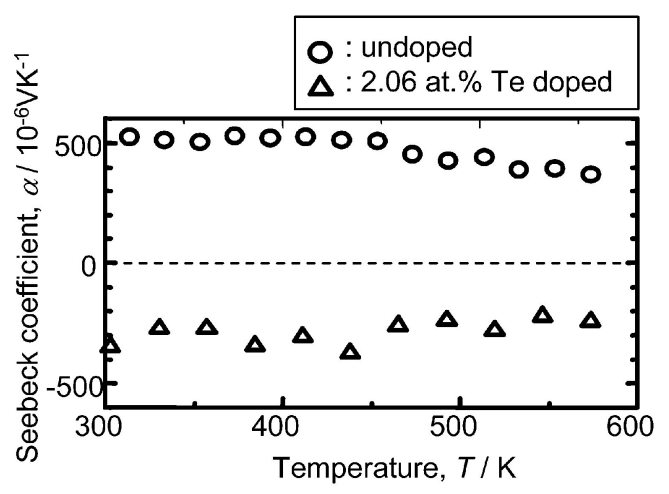

Fig. 4 Seebeck coefficient versus temperature for the undoped $p$-type and the 2.06 at\% Te doped $n$-type samples.

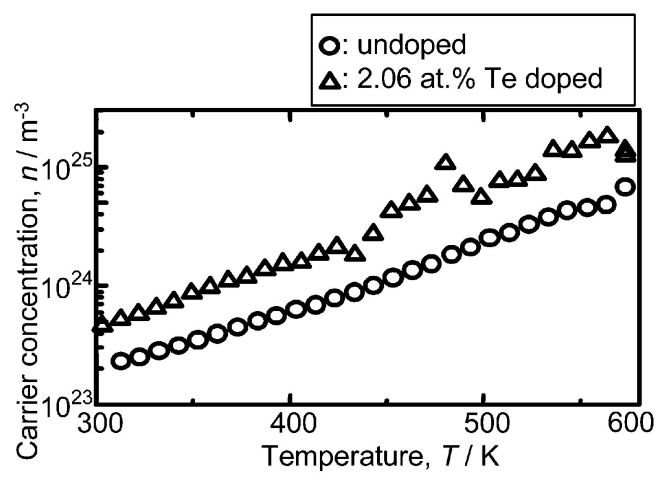

Fig. 5 Carrier concentration $n$ versus temperature for the undoped $p$-type and the 2.06 at $\%$ Te doped $n$-type samples.

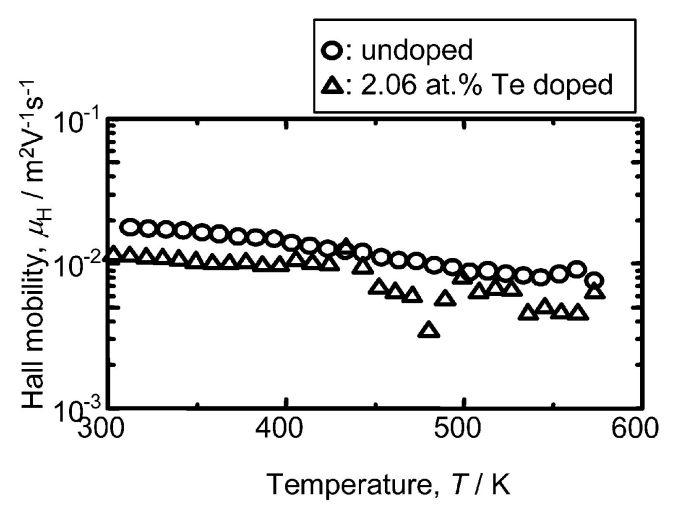

Fig. 6 Hall mobility versus temperature for the undoped $p-$ type and the 2.06 at\% Te doped $n$-type samples.

2.06 at\%テルル元素を添加した $n$ 型サンプルと比較のた めのテルル無添加の $p$ 型サンプルのキャリア濃度の温度依存 性を Fig. 5 に示す。キャリア濃度は, 温度とともに増加傾 向にある. $n$ 型サンプルのキャリア濃度は, テルル無添加の p 型サンプルとほぼ同じ値を示している.

ホール移動度と温度の関係を Fig. 6 に示す.ホール移動 度は，温度の上昇ともに減少傾向にあり， $n$ 型サンプルの ホール移動度と $p$ 型サンプルのホール移動度はほぼ同じ傾向 を示している. Fig. 7 に $300 \mathrm{~K}$ から $600 \mathrm{~K}$ の温度範囲で, 2.06 at\%テルル元素を添加した $n$ 型サンプルと比較のため のテルル無添加の $p$ 型サンプルの電気伝導率の温度依存性を 示す．電気伝導率は，温度の上昇とともに増加する傾向にあ

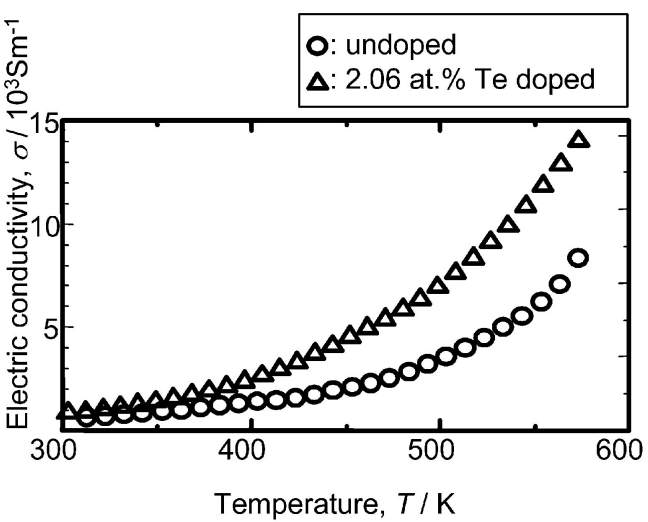

Fig. 7 Electric conductivity versus temperature for the undoped $p$-type and the 2.06 at $\%$ Te doped $n$-type samples.

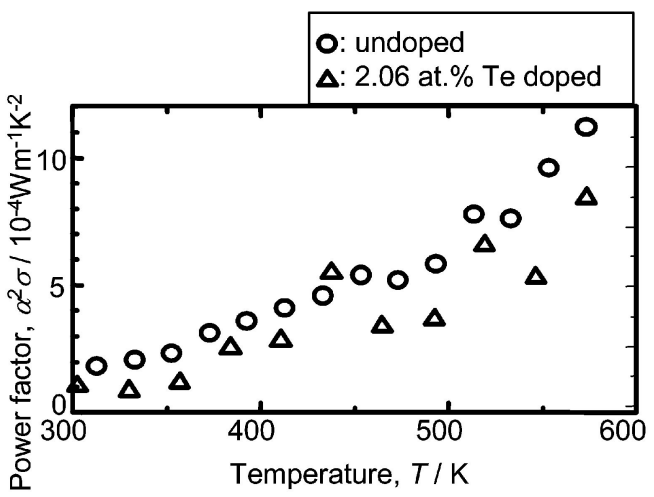

Fig. 8 Power factor estimated from the value of the electric conductivity and the Seebeck coefficient for the undoped $p-$ type and the 2.06 at $\%$ Te doped $n$-type samples.

る.これらの熱電半導体の温度依存性は, 半導体の温度依存 性に一致する.

Fig. 8 に $300 \mathrm{~K}$ から $600 \mathrm{~K}$ の温度範囲で 2.06 at\%テルル 元素を添加した $n$ 型サンプルと比較のためのテルル無添加 の $p$ 型サンプルの電気伝導率とゼーベック係数から計算され るパワーファクターの温度依存性を示す. $573 \mathrm{~K}$ で両サンプ ルの最大のパワーファクターを示し，テルル無添加の $p$ 型サ ンプルのパワーファクターが $1.12 \times 10^{-3} \mathrm{Wm}^{-1} \mathrm{~K}^{-2}$ である のに対し， 2.06 at\%テルル元素を添加した $n$ 型サンプルの パワーファクターは， $0.84 \times 10^{-3} \mathrm{Wm}^{-1} \mathrm{~K}^{-2}$ であった。

\section{4. 結 論}

本研究では, 添加元素としてテルルを使用することでn 型 $\mathrm{ZnSb}$ サンプルを試作した。その結果，以下の知見が得ら れた。

（1） 直接溶解法により $n$ 型単相 $\mathrm{ZnSb}$ サンプル試作するこ とに成功した。

(2) $\mathrm{X}$ 線回折からは, $\mathrm{ZnSb}$ 相のテルル元素の固溶限は 3 at\%未満であることが判明した。

（3） 0, 1, 3 at\%テルル元素を添加した $\mathrm{ZnSb}$ サンプルは， $p$ 型を示した. 一方, 1.9, 2.06 at\%テルル元素を添加した $\mathrm{ZnSb}$ サンプルは, $n$ 型を示した。つまり，適切な量のテル 
ル添加を行えば， $n$ 型 $\mathrm{ZnSb}$ が得られることが明らかになっ た. 過剰な Te は, ZnTe 相の析出の原因となっている。そ のため 3 at\%テルル元素を添加した $\mathrm{ZnSb}$ サンプルは $n$ 型か ら $p$ 型に導電タイプを変化したと考えられる.

(4) $573 \mathrm{~K}$ で両サンプルともに最大のパワーファクター し，テルル無添加の $p$ 型サンプルと 2.06 at\%テルル元素を 添加した $n$ 型サンプルのパワーファクターは，それぞれ $1.12 \times 10^{-3} \mathrm{Wm}^{-1} \mathrm{~K}^{-2}$ と $0.84 \times 10^{-3} \mathrm{Wm}^{-1} \mathrm{~K}^{-2}$ であった.

\section{文献}

1) Y. Suga: Thermoelectric Semiconductor, (Maki Syoten, Tokyo, 1966) pp. 314-317.

2) M. Telkes: J. Appl. Phys. 25 (1954) 765-777.
3) M. Telkes: J. Appl. Phys. 18(1947) 1116-1127.

4) H. Komiya, K. Masumoto and H. Y. Fan: Phys. Rev. A 133 (1964) 1679-1684.

5) K. Masumoto and H. Komiya: J. Japan Inst. Metals 28(1964) 273-281.

6) H. W. Mayer, I. Mikhail and K. Schubert: J. Less-Common Met. 59(1978) 43-52.

7) T. Koyanagi, K. Adachi, K. Kishimoto and K. Matsubara: Trans. IEEJ 116-A (1996) 258-267.

8) K. Hasezaki, M. Nishimura, M. Umata, H. Tsukuda and M. Araoka: 12th Int. Conf. on Thermoelectrics, (ICT, 1993) pp. 307-310.

9) H.-G. Müller and G. Schneider: Z. Naturforsch. 26a(1971) 1316-1322.

10) G. Schneider: Phys. Stat. Sol. 33(1969) K133-K136

11) A. Abou-Zeid and G. Schneider: Phys. Stat. Sol. (a)6(1971) K101-K103.

12) M. S. Hossain, R. Islam and K. A. Khan: Renewable Energy 33 (2008) 642-647. 